\title{
Introduction to Knowledge For The Anthropocene
}

\section{Francisco Javier Carrillo}

Why 'Knowledge for the Anthropocene'? How is this title relevant? Basically, it refers to how these two terms relate to each other. How we understand each of them on their own and then how a new relationship can be constructed between them. Such relationship can in turn set up new inter-determinacies, co-evolving in their subsequent understanding.

The term Anthropocene was introduced to name the proposed geological epoch following the Holocene (Crutzen \& Stoermer, 2000). It is characterized by an overwhelming mark of human activity on Earth so as to leave a geo-stratigraphical record (Zalasiewicz et al., 2010; Zalasiewicz et al., 2019). While there is ongoing debate regarding the starting date of the Anthropocene, a favoured interpretation is to associate it to the 'Great Acceleration': the surge of human impact on Earth since the mid-20th century (Steffen, Broadgate et al., 2015; McNeill \& Engelke, 2016). Given the enormous significance of these facts and the observed and potential consequences for the Biosphere, the term has also been adopted to comprise its wider social, economic and cultural implications (Castree, 2017; Cohen \& Colebrook, 2017; Malabou, 2017; Clark \& Szerszynski, 2021). This book adopts the wider use insofar as it conveys an essentially transdisciplinary 'Anthropocenic turn' in contemporary culture (Oldfield et al., 2014; Hamilton et al., 2015; Carrillo, 2019; Dürbeck \& Hüpkes, 2020; Krogh, 2020).

Anthropogenic environmental impacts are heading to disrupt our way of life in deeper ways and at a wider scale than anything previously experienced by mankind. The public imaginary and the media often reduce the Anthropocene challenges to both Climate Change and Global Warming. Within this narrative, even when there is an acceptance that these are caused by human action, the tone is of some climate discomfort and eventual weather hazards that can be dealt with by greater resilience and appropriate technology. These are such diluted and politicized terms that both are being replaced by the most compelling 'Climate Crisis' or 'Climate Emergency' and 'Global Heating' respectively (Carrington, 2019; Ripple et al., 2019). Local discourses also tend 
to replace anodyne labels with more compelling ones, such as 'from warming to warning' (Manning, 2020).

Actually, the Climate Emergency is only one of nine anthropogenic vectors of Earth System disruption, each having the potential to severely lessen the human habitability of our planet. These are: Climate Change, Novel Entities (anthropogenic objects, materials and bio-actants), Stratospheric Ozone, Atmospheric Aerosol Loading (anthropogenic particles in the Atmosphere), Ocean Acidification, Biogeochemical Flows (Nitrogen and Phosphorus cycles), Freshwater Use, Change in Land Use and Biodiversity Loss (Extinction rate). Each of these 'Planetary Boundaries' is sustained by a delicate balance required to keep a 'Safe Operating Space' for Humanity (Rockström et al., 2009). Hence, trespassing each of these Planetary Boundaries conveys an Existential Risk to Humanity (Barnosky et al., 2012; Steffen, Richardson et al., 2015).

While Anthropogenic Global Existential Risks challenge the conditions of the Biosphere that prevailed through the Holocene, the existing social knowledge base seems inadequate to help us cope with such realities (Castree et al., 2014; Clark \& Szerszynski, 2021). The idea of knowledge as a global transformative force shaped the concept of 'the Noosphere' in the early 1920s, thanks to the convergence of independent work by geologist Vladimir Vernadsky, philosopher Pierre Theilard de Chardin and mathematician Édouard Le Roy. They shared the idea of an evolutionary layer or global developmental stage based on reason, science and technology. Vernadsky, with his scientific background in biogeochemistry, was able to ground the concept in natural science.

The relationship between the Anthropocene as a geological epoch and human knowledge was noticed early (Crutzen \& Stoermer, 2000, p. 17). However, the relationship between the Anthropocene and human knowledge goes well beyond an aspirational stage of evolution. Reflexively, modern Western technoscientific and economic culture has also been regarded as a major underlying driver of the Anthropocene, requiring to 'recognize the more radical normative implications' (Castree, 2017, p. 64). Hence, the knowledge-based culture accompanying the Great Acceleration has been regarded both as cause and potential solution (O'Brien, 2016; Castree, 2017; Cohen and Colebrook, 2017; Malabou, 2017; Few et al., 2021), a corollary of the basic tenet in Science and Technology Studies regarding the inter-determinacy between knowledge and society (Felt el al., 2016). On the one hand, we need to understand how our current knowledge practices and institutions have brought us here; such understanding requiring a new critical perspective in itself. On the other hand, we need to reinvent the knowledge systems that might still enable us to adapt to and mitigate anthropogenic impacts and, above all, to redefine the terms of relation between humans and planet Earth. 
Chapters in this book address different aspects of knowledge, the Anthropocene, and the relation between both. While a diversity of approaches and perspectives has been welcomed and actively encouraged, the concept of knowledge system (KS) as an integrative framework resonates through several chapters. According to the concept developed at the Center for Knowledge Systems, ${ }^{1}$ a KS is 'the alignment of value dimensions between an object, an agent and a context of knowledge' (see, e.g., Carrillo, 1998; Carrillo et al., 2019). While such concept allowed a very effective characterization of knowledge management processes over a quarter of a century, each of the core categories and perhaps the very idea of a knowledge system is in need of a major overhaul. Knowledge objects multiply and diversify, in a flat ontology realm such as the democracy of the beings proposed by Object-Oriented Ontology (Harman, 2018). Suddenly, objects and materials are not regarded anymore as inert entities, but come alive, as it were, in an entangled network of actors where texts, instruments, symbols, concepts, and so on stop being passive recipients of transitive action and engage themselves as agents.

Accordingly, knowledge agents morph into the rhizomatic universe of the others, a re-encounter with alterity and an openness towards the more-than-human world. The human is demoted from the centre of history and diluted into a geological scale. The casting of the knowledge theater explodes in a diaspora of characters that tends to correspond with the diversity of the world. The voices of the local, feminist, native, traditional, domestic, pragmatic, and other majorities at large formerly silenced or ignored by the anthropo- and euro-centric, male, white, colonial, capitalist worldview anchored in the knowledge establishment reclaim their stand, giving way to a societal and global choir (Braidotti, 2017). Beyond that, the more-than-human voices of the living and non-living allow the creatures and the critters, the mountain and the river, the galaxy and the molecule, to regain agency and co-design the world (Haraway, 2016).

Above all, knowledge contexts are harder to make sense of because the value systems providing semantic significance and economic worth have been falling apart. One by one, the foundational categories of modernity are demolished by the deconstructive fever of the postmodern. In parallel, the globalized capitalist establishment implodes in an ever increasing and paradoxical concentration and nullification of wealth. Politics is polarized and atomized into the party of each individual, only for identity to be further disaggregated into quantum events.

Hence, the known knowns of object, agent and context became known unknowns. The post-truth society challenges not just the public awareness of the climate emergency but the very possibility of public knowledge. A more robust foundation of a pragmatic common axiological base (capital system) is required. A 'genuine climate change' entails a new materiality: a basic 
common understanding on 'the things that matter' (Cohen \& Colebrook, 2017, p. 135). Certainly, the Climate Emergency forces us to reconsider our common value base or capital system (Aeron-Thomas et al., 2004; Gleeson-White, 2015; Dietz et al., 2020; Gough, 2020). Seeking knowledge for the Anthropocene largely becomes learning to manage what matters to people: Managing Knowledge-based Value Systems (Carrillo, 1998; O’Brien \& Wolf, 2010; Albizua \& Zografos, 2014).

The existential challenges of the Anthropocene thus confront us with a double task: to redefine posthuman knowledge and to do so before the unprecedented and highly complex circumstances of the unfolding futures. Knowledge systems for the Anthropocene are cognitive hyperobjects (Morton, 2013) distancing from the past and evading predetermined futures.

Hence, if there is going to be a Knowledge for the Anthropocene, it has yet to be imagined. Not only the foundational questions of knowledge will need to be reset. The primordial categories will need to be defined afresh. What is to be known? Who will know? Who will benefit? For what purpose? What will be relevant dimension for aligning objects, agents and contexts in Anthropocenic knowledge systems? Knowledge discourses will have to be advanced upon new axes. Whose will be the narrative voice in a more-than-human history at once being challenged with survival and subsumption into a cosmic consciousness?

The monumental task of reinventing a knowledge for the Anthropocene is only rivalled by the challenge of articulating the global human experience, so that the urgent supranational policies required to enact viable futures are agreed and enforced. Or perhaps they are interdependent: 'Could it be that new histories of mentalities, which would bring together the geological, biological, and cultural current dimensions of historical (non) awareness, may open a new chapter of Anthropocenic study?' (Malabou, 2017, p. 52). The circumstance of the Anthropocene is at once an existential threat and an ontological option: 'Humanity is an effect of being unified by a critical condition' (Cohen \& Colebrook, 2017, p. 130).

Hence, the set of chapters constituting this book aim at shedding some light upon these questions. Rather than individual chapters providing separate answers, it is their collective transdisciplinarity that becomes meaningful. Even in their plurality and intersectionality, the set of contributions compounds a mosaic that might help to articulate the "new chapter of Anthropocenic study'.

The time is ripe for a publication like this book. Certainly, there is a substantial set of precursors from different disciplines to different aspects of understanding knowledge in the Anthropocene, as several of the contributions to this book show. Amongst the now abundant literature on Anthropocene-related issues, a large portion of works will somehow deal with aspects of knowledge. Actually, a substantial collection of works that do not mention knowledge for 
the Anthropocene per se, provide some of the seminal contributions to chapters covered by this book.

Yet, Knowledge in the Anthropocene as an analytic category on its own, has only partially been addressed in different platforms. The 2017 Special Issue of the South Atlantic Quarterly on 'Climate Change and the Production of Knowledge' (edited by Baucom \& Omelsky, 2017) has been one of the most substantial precursors, while the abovementioned 2019 Editorial of the International Journal of Knowledge Based Development (Carrillo, 2019) incorporated this topic into the IJKBD editorial scope. Within scientific periodicals probably the special issue of Current Opinion in Environmental Sustainability on 'Advancing the science of actionable knowledge for sustainability' (Arnott et al., 2020) constitutes the most substantial recent contribution.

A more consistent channel of focused contributions has been that of individual papers in scientific journals (e.g., Baghel, 2012; Homsy \& Warner, 2013; Seidl et al., 2013; Perret, 2014; Wark \& Jandrić, 2016; Delanty \& Mota, 2017; Edwards, 2017; Turnhout, 2018; Nakagawa \& Payne, 2019; Featherstone, 2020; Jensen, 2020: Schemmel, 2020). The recently published study by Fazey et al. (2020) directly addresses issues related to the design of Knowledge Systems for the Anthropocene. Also, some research centres or think tanks besides the WCI case described above, are vesting dedicated efforts specifically to issues of knowledge in the Anthropocene, such as the Responses to Environmental and Societal Challenges for our Unstable Earth (RESCUE) Program running from 2009 through 2011 (Jäger et al., 2011) or the ongoing Changing Ecologies of Knowledge (CEKA) at the University of Oxford Institute for Science Innovation and Society.

In terms of books the contributions have so far been rather marginal. While the subheading to Section 1 of Dürbeck \& Hüpkes' book (2020) is 'Creating Knowledge for the Anthropocene', chapters included deal with historical, metaphysical and cultural aspects of the Anthropocene. These are certainly important in the context of interdisciplinary approaches to the Climate Emergency but cover little in terms of knowledge systems and processes. Similarly, Renn's (2020) evolutionary account of the history of science from a cognitive structuralist perspective includes a chapter (16th of 17) on Knowledge for the Anthropocene that works as an epilogue and 'further research' section. While his monumental reconstruction of the history of science and technology is a landmark contribution, his incursion on our core topic remained incidental.

This book constitutes the first volume wholly and directly concerned with issues related to Knowledge in the Anthropocene. If knowledge is the most important leverage to human action and the leading force to civilization, how can our knowledge societies come to terms with the foreseeable realities of the climate crisis and face the emergency in the best possible way? What relevant knowledge will become critical to cope with deteriorating environmental 
conditions? How can science, technology, innovation and education be radically transformed for adequately responding? How can governments continue to serve their purpose? How need our mind frames evolve? These and other related questions are addressed in a direct and accessible manner by a set of international specialists. The common purpose is to provide a general perspective on the role that knowledge - the most important leverage to human action, may need to play in our not-so-distant future.

\section{NOTE}

1. The Center for Knowledge Systems operated at Tecnológico de Monterrey, México, from 1989 through 2014. Throughout its 25 years of existence, it was fully self-sufficient due to its combination of consultancy with research and teaching. The CKS mission statement was "To leverage the value creation capacity of individuals, organizations and societies through the research, design, implementation and learning on knowledge systems." Since 2013 it became the basis for the Strategic Research Group on Knowledge Societies.

\section{REFERENCES}

Aeron-Thomas, D., Nicholls, J., Forster, S., \& Westall, A. (2004). Social return on investment: Valuing what matters. New Economics Foundation.

Albizua, A., \& Zografos, C. (2014). A values-based approach to vulnerability and adaptation to climate change. Applying Q methodology in the Ebro Delta, Spain. Environmental Policy and Governance, 24(6), 405-422.

Arnott, J.C., Mach, K.J., \& Wong-Parodi, G. (eds) (2020). Special Issue on advancing the science of actionable knowledge for sustainability. Current Opinion in Environmental Sustainability, 42 (February), A1-A6, 1-82.

Baghel, R. (2012). Knowledge, power and the environment: Epistemologies of the Anthropocene. Transciencie, 3(1), 1-6.

Barnosky, A.D., Hadly, E.A., Bascompte, J., Berlow, E.L., Brown, J.H., Fortelius, M., ... \& Martinez, N.D. (2012). Approaching a state shift in Earth's biosphere. Nature, 486(7401), 52-58.

Baucom, I., \& Omelsky, M. (2017). Knowledge in the age of climate change. South Atlantic Quarterly, 116(1), 1-18.

Braidotti, R. (2017). Critical posthuman knowledges. South Atlantic Quarterly, 116(1), 83-96.

Carrillo, F.J. (1998). Managing knowledge-based value systems. Journal of Knowledge Management, 1(4), 280-286.

Carrillo, F.J. (2019). The Anthropocene turn in knowledge based development. International Journal of Knowledge-Based Development, 10(4), 293.

Carrillo, F.J., Edvardsson, B., Reynoso, J., \& Maravillo, E. (2019). Alignment of resources, actors and contexts for value creation. International Journal of Quality and Service Sciences, 1-31. doi.org/10.1108/IJQSS-08-2018-0077.

Carrington, D. (2019, 17 May). Why the Guardian is changing the language it uses about the environment. Last retrieved on 25 December 2020, from https://www 
.theguardian.com/environment/2019/may/17/why-the-guardian-is-changing-the -language-it-uses-about-the-environment.

Castree, N. (2017). Global change research and the 'people disciplines': Toward a new dispensation. South Atlantic Quarterly, 116(1), 55-67.

Castree, N., Adams, W. M., Barry, J., Brockington, D., Büscher, B., Corbera, E., ... \& Newell, P. (2014). Changing the intellectual climate. Nature Climate Change, 4(9), 763-768.

Clark, N., \& Szerszynski, B. (2021). Planetary social thought: The Anthropocene challenge to the social sciences. John Wiley \& Sons.

Cohen, T., \& Colebrook, C. (2017). Vortices: On 'critical climate change' as a project. South Atlantic Quarterly, 116(1), 129-143.

Crutzen, P.J. and Stoermer, E.F. (2000). The Anthropocene. IGBP Newsletter 41. Royal Swedish Academy of Sciences.

Delanty, G., \& Mota, A. (2017). Governing the Anthropocene: Agency, governance, knowledge. European Journal of Social Theory, 20(1), 9-38.

Dietz, T., Shwom, R.L., \& Whitley, C.T. (2020). Climate change and society. Annual Review of Sociology, 46, 5.1-5.24.

Dürbeck, G., \& Hüpkes, P. (eds) (2020). The Anthropocenic Turn: The Interplay Between Disciplinary and Interdisciplinary Responses to a New Age. Routledge.

Edwards, P. N. (2017). Knowledge infrastructures for the Anthropocene. The Anthropocene Review, 4(1), 34-43.

Fazey, I., Schäpke, N., Caniglia, G., Hodgson, A., Kendrick, I., Lyon, C., ... \& Verveen, S. (2020). Transforming knowledge systems for life on Earth: Visions of future systems and how to get there. Energy Research \& Social Science, 70, 101724.

Featherstone, M. (2020). Stiegler's ecological thought: The politics of knowledge in the anthropocene. Educational Philosophy and Theory, 52(4), 409-419.

Felt, U. et al. (2016). The handbook of science and technology studies, The MIT Press, 253.

Few, R., Spear, D., Singh, C., Tebboth, M.G., Davies, J.E., \& Thompson-Hall, M.C. (2021). Culture as a mediator of climate change adaptation: Neither static nor unidirectional. Wiley Interdisciplinary Reviews: Climate Change, 12(1), e687.

Gleeson-White, J. (2015). Six capitals, or can accountants save the planet?: Rethinking capitalism for the twenty-first century. WW Norton \& Company.

Gough, I. (2020). In times of climate breakdown, how do we value what matters? Open Democracy. Last retrieved on 24 February 2020, from https://www.opendemocracy .net/en/oureconomy/times-climate-breakdown-how-do-we-value-what-matters/.

Hamilton, C., Gemenne, F., \& Bonneuil, C. (eds) (2015). The Anthropocene and the global environmental crisis: Rethinking modernity in a new epoch. Routledge.

Haraway, D.J. (2016). Staying with the trouble: Making kin in the Chthulucene. Duke University Press.

Harman, G. (2018). Object-oriented ontology: A new theory of everything. Penguin UK.

Homsy, G.C., \& Warner, M.E. (2013). Climate change and the co-production of knowledge and policy in rural USA communities. Sociologia Ruralis, 53(3), 291-310.

Jäger, J., Pálsson, G., Goodsite, M., Pahl-Wostl, C., O’Brien, K., Hordijk, L., \& Avril, B. (2011). Responses to environmental and societal challenges for our unstable earth (RESCUE), ESF Forward Look-ESF-COST 'Frontier of Science' joint initiative. RESCUE report. 
Jensen, C.B. (2020). The Anthropocene eel: Emergent knowledge, ontological politics and new propositions for an age of extinctions. Anthropocenes - Human, Inhuman, Posthuman, 1(1).

Krogh, M. (ed.) (2020). Connectedness. An incomplete encyclopedia of the Anthropocene. Strandberg Publishing.

Malabou, C. (2017). The brain of history, or, the mentality of the Anthropocene. South Atlantic Quarterly, 116(1), 39-53.

Manning, P. (2020). Body count - how climate change is killing us. Simon \& Schuster Australia.

McNeill, J.R., \& Engelke, P. (2016). The great acceleration: An environmental history of the Anthropocene since 1945. Harvard University Press.

Morton, T. (2013). Hyperobjects: Philosophy and ecology after the end of the world. University of Minnesota Press.

Nakagawa, Y., \& Payne, P.G. (2019). Postcritical knowledge ecology in the Anthropocene. Educational Philosophy and Theory, 51(6), 559-571.

O'Brien, K. (2016). Climate change adaptation and social transformation. In Richardson, D. et al., International Encyclopedia of Geography: People, the Earth, Environment and Technology, Wiley-Blackwell, 1-8.

O'Brien, K.L., \& Wolf, J. (2010). A values-based approach to vulnerability and adaptation to climate change. Wiley Interdisciplinary Reviews: Climate Change, 1(2), 232-242.

Oldfield, F., Barnosky, A.D., Dearing, J., Fischer-Kowalski, M., McNeill, J., Steffen, W., \& Zalasiewicz, J. (2014). The Anthropocene review: Its significance, implications and the rationale for a new transdisciplinary journal. The Anthropocene Review, 1(1) 3-7.

Perret, M. (2014). Amphibians, affect and agency: On the production of scientific knowledge in the Anthropocene. Berkeley Undergraduate Journal, 27(2), 132-159.

Renn, J. (2020). The evolution of knowledge: Rethinking science for the Anthropocene. Princeton University Press.

Ripple, W., Wolf, C., Newsome, T., Barnard, P., Moomaw, W., \& Grandcolas, P. (2019). World scientists' warning of a climate emergency. BioScience. Last retrieved on 24 February 2020, from: https://hal.archives-ouvertes.fr/hal-02397151.

Rockström, J., Steffen, W., Noone, K., Persson, Å., Chapin III, F.S., Lambin, E., ... \& Nykvist, B. (2009). Planetary boundaries: Exploring the safe operating space for humanity. Ecology and Society, 14(2), 32-64.

Schemmel, M. (2020). Global history of science as a knowledge resource for the Anthropocene. Global Sustainability 3(22), 1-8.

Seidl, R., Brand, F.S., Stauffacher, M., Krütli, P., Le, Q. B., Spörri, A., ... \& Scholz, R.W. (2013). Science with society in the Anthropocene. Ambio, 42(1), 5-12.

Steffen, W., Broadgate, W., Deutsch, L., Gaffney, O., \& Ludwig, C. (2015). The trajectory of the Anthropocene: The great acceleration. The Anthropocene Review, 2(1), 81-98.

Steffen, W., Richardson, K., Rockström, J., Cornell, S.E., Fetzer, I., Bennett, E. M., ... \& Folke, C. (2015). Planetary boundaries: Guiding human development on a changing planet. Science, 347(6223).

Turnhout, E. (2018). The politics of environmental knowledge. Conservation and Society, 16(3), 363-371.

Wark, M., \& Jandrić, P. (2016). New knowledge for a new planet: Critical pedagogy for the Anthropocene. Open Review of Educational Research, 3(1), 148-178. 
Zalasiewicz, J., Waters, C.N., Williams, M., \& Summerhayes, C.P. (eds) (2019). The Anthropocene as a geological time unit: A guide to the scientific evidence and current debate. Cambridge University Press.

Zalasiewicz, J., Williams, M., Steffen, W., \& Crutzen, P. (2010). The new world of the Anthropocene. Environmental Science and Technology, 44, 2228-2231. 